VI.-On the Mode in which Musket-Bullets and other Foreign Bodies become inclosed in the Ivory of the Tusks of the Elephant. By JoHN Goodsin, Esq. M. W.S. Communicated by Professor Syme.

(Read i8th January 1841.)

MUSKET-BULLETS are occasionally found inclosed in ivory, and every anatomical museum contains specimens of this kind. Why bullets should be so frequently met with in this situation, it is not easy to say; the head of the animal appears to be generally aimed at, and foreign bodies when they enter the tusks, instead of being removed in the usual manner, are retained by the process, an investigation of which is to form the subject of the present paper.

My attention was directed to this subject by Mr Syme, who submitted to me for examination some highly interesting specimens of bullets in ivory, presented to the Anatomical Museum of the University by Sir John Robrson. Sir JoHn has also kindly afforded me an opportunity of examining some remarkable examples of wounded ivory, and Sir GEorge Ballingall has directed my attention to preparations in his possession, which have satisfied me of the truth of those opinions on the subject, which I shall now have the honour of submitting to the Society.*

One circumstance was at once detected in all these specimens, and its importance was evident, as affording a clew to the explanation of the mode of inclosure. The circumstance to which $I$ allude is, that in none of the specimens are the bullets or foreign bodies stirrounded by regular ivory. They are in every instance inclosed in masses, more or less bulky, of a substance which, although abnormal in the tusk of the elephant, is never heless well known to the comparative anatomist, as occupying the interior of the teeth of some of the other mammals, and usually considered to be ossified pulp. It was evident that the pulp had ossified round the bullet, as the first step towards the separation of the latter from it. In one specimen the bullet has become enveloped in a hollow sphere of this substance, on the surface of which the orifices of medullary canals are situated. In other specimens the irregular ivory, which surrounds the balls, had become smooth on its surface, the medullary canals had disappeared, and the regular ivory had been formed in a continuous layer over the surface of the mass. In

* We are indebted for the specimens to the liberality of Mr Rodgers of Sheffield, who transmitted to Sir John Rodison for examination, these as well as many other most remarkable examples of wounded and diseased tusks. 
one tusk a cicatrix was seen occupying the hole through which the ball had passed, a circumstance which, when seen in similar specimens, has greatly perplexed anatomists. It was observed, however, that, in this instance, the shot had passed through that part of the tusk which had been within the socket; and bearing in mind that the tusk is an organ of double growth, it appeared probable that the shot had been plugged up from within by the ossified pulp, and from without by the continued growth of cement, without any regeneration of the displaced ivory; a hypothesis which was afterwards verified by examination.

Before proceeding to give a more detailed account of this interesting process, I shall state very briefly the opinions of those authors who have written on the subject, so as to ascertain how near they had approached to the truth, and to point out the fallacies which had led them astray.

KLOCKNER mentions a ball of gold which was found by a turner of Amsterdam in the substance of an elephant's tusk. The longitudinal fibres of the tusk surrounded the metal in an irregular manner, and were separated from the sound ivory by a concentric chink situated at some distance from the ball.

CAMPER in the "Description Anatomique d'un Elephant Male," remarks, that it is not unusual to see foreign bodies inclosed, or as it were soldered, into the substance of the ivory. The same anatomist also figures and describes a bullet which was inclosed in a very irregular mass of ivory, covered with long appendages, which were directed parallel to the axis of the tusk. The metallic bodies in question, he remarks, must have penetrated across the alveolus into the hollow of the tusk, and must have remained for a long time in the substance of the pulpy flesh which fills that cavity, because the ivory enveloped them on all sides, and would at length have carried them beyond the alveolus by the increase of the tooth. He supposes that the nodules which are formed around the balls, and the very incomplete union of their fibres with the sound ivory, add weight to this conjecture.

Ruysch in his X. Thesaurus, Plate II., figures brass and iron bullets inclosed in isolated nodules of irregular ivory.

BLumenbach considers the tusks of the elephant to differ from other teeth, more particularly in the remarkable pathological phenomenon of bullets, with which the animal has been shot, being found, on sawing through the tusk, imbedded in its substance in a peculiar manner. He looks upon this fact as important in reference to the doctrine of a " nutritio ultra vasa." He mentions a tusk, equal in size to a man's thigh, in which an unflattened leaden bullet lay close to the cavity of the tooth, surrounded by a peculiar covering, and the entrance from without closed as it were by a cicatrix. From these facts Blumenbach concludes that the elephant's tusk, when fractured or perforated, can pour out an ossific juice to repair the injury.

Mr Lawrence, in his Notes to Blumenbach's Comparative Anatomy, over- 
looking those cases (one of which is given in the text of his author) in which cicatrices have been seen filling up the orifices produced by balls, explains satisfactorily enough those instances in which no such cicatrices exist, and concludes by denying the power of the ivory to throw out ossific matter as asserted by BuUMENBACH.

The author of the Ossemens Fossiles, in his chapter on the structure, development, and diseases of the tusks of the elephant, after stating that grooves and notches on the surfaces of the tusks never fill up, and only disappear from the effects of friction, allows that musket-balls are found in ivory without any apparent hole by which they could have entered. He does not believe that the holes are filled up with ossific deposition as HALLer and Blumenbach supposed; but maintains that they are never obliterated. He states that the ivory on the outside of the ball is natural, and that it is only the bone surrounding it which is irregular. The phenomena are to be explained, he says, by supposing the balls to penetrate the very thin bases of tusks in young elephants, so as to enter the pulps when still in a growing state.

There appear, then, to be two circumstances, regarding which great doubts still exist-first, whether a shot-hole is ever closed up; and, secondly, how this is accomplished in a non-vascular substance like ivory.

In proceeding to consider this subject, two facts must be borne in mind in reference to a tusk. The first is, that the two substances of which it is composed, ivory and cement, undergo no change of form or arrangement from vital action, after they are once deposited; the second, that it is an organ of double growthit is endogenous as well as exogenous, the ivory being formed from without inwards, the cement from within outwards.

As there are certain processes which invariably commence when a foreign body passes through or lodges in the pulp, it will facilitate the conception of the mode in which a bullet is inclosed if these be described first.

Recent researches have proved that the regular ivory of teeth is formed by the cells on the surface of the pulp becoming solid from the deposition of earthy salts in their walls and cavities. It is evident from this that, when a portion of the surface of the tusk-pulp is destroyed by the passage of a ball, the formation of ivory at that spot must cease. But we know that the formation of irregular ivory commences, which indicates the existence of a healing process in the pulp. The mode in which the wounded pulp heals, cannot be ascertained; but it is accomplished probably by effusion and subsequent absorption of blood, de. position of lymph, and regeneration of the peculiar tissue of the pulp. So far this process is conjectural, but the irregular ivory formed by the regenerated pulp is the subject of observation. When the ball passes quite across the pulp the track heals, but does not necessarily ossify, except in the immediate neighbourhood of the ivory. 
There are two exceptions, however, to the non-ossification of the track of the ball, namely, the ossification which takes place round the bullet, and that which occurs round the whole or any portion of the track, which may suppurate and form a sinus or abscess. In both these cases deposition of irregular ivory takes place, assuming the same characters as the irregular masses which appear at the two extremities of the track of the ball through the pulp.

The ossification round the ball generally assumes the form of a hollow sphere. Its surface exhibits a number of holes (which are the orifices of medullary canals), and these are occasionally prolonged through stalactitic-looking processes, which lie in the direction of the axis of the tooth. The ossification surrounding an abscess or sinus assumes the appearance of a shell of variable thickness, and directed towards one or both of the shot-holes.

When thin sections of this irregular ivory are examined under the microscope, it is seen to consist of a transparent matrix, in which exist numerous medullary canals, shewing traces of dried pulp in their interior. From these canals, which correspond to the Haversian canals of true bone, secondary medullary canals, similar to those in the teeth of certain fishes, radiate. The sides and extremities of these secondary medullary canals send off numerous minute tubes, which are true Retzian tubes, and similar to those in the regular ivory, but not so closely set. These Retzian tubes have a general radiating direction, and proceed in irregular wavy bundles, which sweep past one another without mingling, but branching particularly at their extremities. The great central medullary canals are very numerous, and each of them has its own system of secondary canals and Retzian tubes.

These individual systems, when seen in a mass of irregular ivory, appear globular or spindle-shaped; when viewed in section, they resemble circular or oval opaque spots with a hole in the centre. These individual systems, however, are not isolated; for they communicate, first, by means of the central canals, which constitute an inosculating system; and, secondly, by the ramifying extremities of the Retzian tubes, which communicate through the medium of cells more or less minute, and which are more numerous in some places than in others.

The formation of the irregular ivory does not go on indefinitely: a limit is set to its increase, and the changes which ensue at this stage of the process are highly interesting. I have already mentioned the existence of the orifices of Haversian, or medullary canals on the surface of the mass of irregular ivory. When the further formation of this is to terminate, these orifices are gradually closed, and appear like imperforated projections on the surface. It is evident, therefore, that the inclosed vascular contents of the canals, that is to say, the ramified processes of the tusk-pulp in the irregular ivory, are cut off from the system. They dry up, and the formation of ivory in the interior ceases. The peripheral surface of the irregular ivory is now, in reference to the general pulp, in 
the same relation as the whole internal surface of the irregular ivory of the tusk. The pulp, therefore, becomes converted into ivory, not only on the whole internal surface of the tusk, but also on the surface of the newly-formed mass. The cause of the formation of the irregular ivory to a limited extent only, when it exists as an abnormal structure, I have not been able to ascertain; but its mode of development and limitation is highly interesting, and forms a leading distinction between a tooth and a true bone under similar circumstances.

From this description it is evident that the abnormal ivory in the elephant's tusk strongly resembles, if it be not identical with, the peculiar substance which fills the pulp-cavities of the tusks of the walrus and the teeth of the cetacea, first announced as a distinct species of dentar tissue in a paper read before this Society five years ago by Dr Knox, and since minutely described by Retzius, Owen, and AlEXANDER NASMYTH.**

This identity of a diseased structure in one animal with a normal structure in another is remarkable, and must be looked upon as another instance indicating the existence of a system of laws regulating the relations between healthy and morbid tissues;--laws which have been speculated upon, but have never been sufficiently investigated by anatomists.

Having now given the anatomical characters of the abnormal ivory which invariably surrounds musket-bullets and other foreign bodies which lodge in the pulps of the tusks of the elephant, I shall proceed to state the various conditions under which these enter the organ, and the changes which ensue.

Foreign bodies enter the tusk in three ways: First, through the free portion of the tusk; secondly, through that part of the organ which is contained in the socket; and, thirdly, from above through the base of the pulp.

First, When the ball hits the free portion of the tusk, if it only penetrates to a certain depth of the ivory, no change whatsoever can take place. Neither the cement nor the ivory can be reproduced. In course of time the hole may be obliterated, the ball may be got rid of by wearing down of the ivory, and the ivory

* Cuvier described this species of dental tissue in the tusk of the walrus, and compared it to pudding-stone. Dr Knox, in the paper to which I have referred in the text, affirmed that, in addition tc. the cement, enamel, and ivory, a fourth substance, namely, the substance described by Cuvier, entered into the formation of many teeth. He stated that, in the teeth of certain fishes, this substance, or a tissue closely allied to it, constituted the greater part of their mass; the other three elements having disappeared or become greatly diminished in bulk or importance. Retzius has accurately described the microscopic structure of this class of dental substances, as existing in different animals. Mr Owen has extended and confirmed the observations of Retzius. Lastly, to Mr A. Nasmyth belongs the merit of having pointed out the resemblance which this kind of substance (which he denominates ossified pulp) bears to diseased ivory in the tusks of the elephant, and still more closely to the substance which fill: the pulp cavity of the aged human tooth. In ignorance of Dr KNox's previous observations, he announced this kind of ivory as a fourth dental substance. 
under the hole may be strengthened by the formation of new substance. When the ball is detained by the ivory, but penetrates so far as to wound the pulp, the latter ossifies round it, and the ossified portion sooner or later becomes enveloped in new ivory. If the ball penetrates the pulp, the latter ossifies round it, and becomes attached to the hole in the ivory. If the tusk is growing rapidly, and the nucleus of pulp-bone does not speedily adhere to it, the ball will ultimately be situated above the hole. The ball may also pass across the pulp, and become at last enveloped, along with its bony envelope, in the ivory of the opposite wall.

Second, In the second class of wounds, in which the ball enters the pulp-cavity through the socket and side of the tusk, the consequent changes seem to be the following: first, ossification of the pulp surrounding the ball, and the ultimate application of the mass to the hole in the ivory, and, as the latter is necessarily at this part of its extent very thin, the hole is closed; second, the application to the hole in the ivory, and to the surface of the ossified pulp in it, of cement formed by the internal surface of the tusk-follicle. For although the ball may have removed or at least torn the follicle opposite the hole in the ivory, yet, as the tooth advances in the socket, the ball will in time arrive at a sound portion of the latter. There is a specimen on the table which proves that the wounded portion of the follicle may perform this duty sufficiently well. In this specimen the external surface of the cement exhibits a longitudinal fissure, with smooth rounded edges, resulting from the defective formation of cement in the situation of a longitudinal rent or wound in the membrane of the follicle, through which the ball had entered the ivory. The hole in the ivory then being plugged up externally by cement, and internally by ossified pulp, the case proceeds as in the last class of wounds, - the ossified portion of the pulp surrounding the ball becoming inclosed in true ivory.

Third, When the foreign body enters from above, without wounding the tusk, the pulp ossifies round it, and true ivory envelopes the mass, in the usual manner. I have not seen any morbid ivory which could be referred to wounds of the class now under consideration; but a very interesting account is given by $\mathrm{Mr}$ CoMB, in the Philosophical Transactions," of a tusk in which a spear-head was found, and which could only have entered the cavity from the base of the pulp. Mr CoмB describes and figures the ossified portion of the pulp, and the manner in which it had attached itself to the ivory, and become covered by it, so as to obliterate partially, and to alter the relative width of the pulp-cavity.

The description I have now given of the changes which ensue on wounds of the tusks of the elephant, explains many curious appearances in ivory, and the difficulties anatomists and physiologists have had in understanding them. It explains the drawings and descriptions of Klockner, RuYsch, and CAmper; does away with the necessity of supposing, with BLUMENBACH, that true ivory is regenerated, 

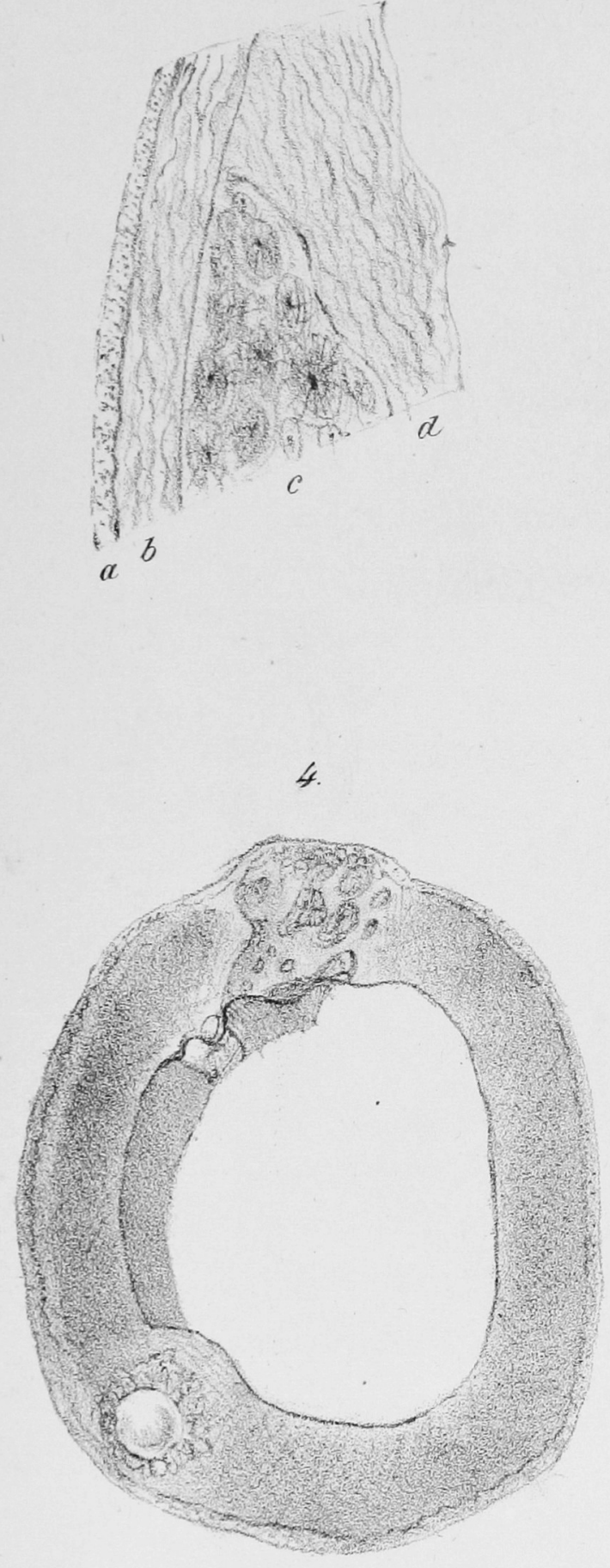

7

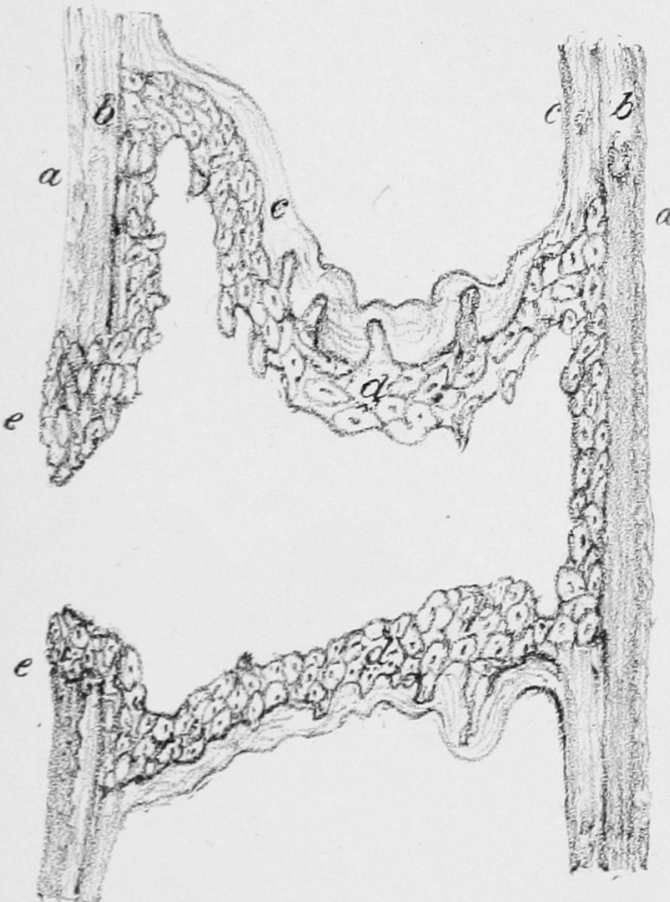

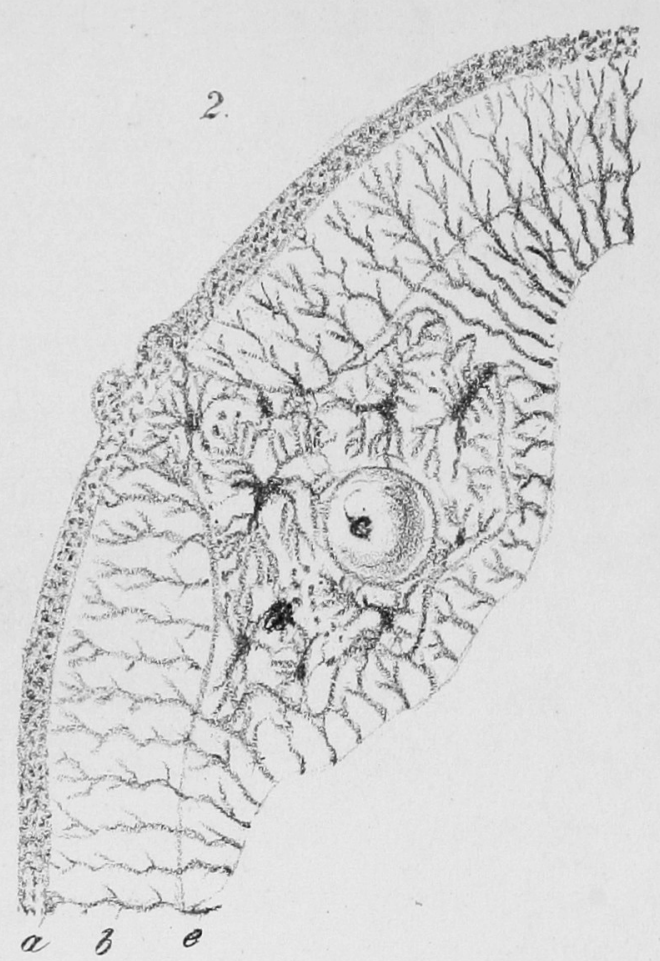
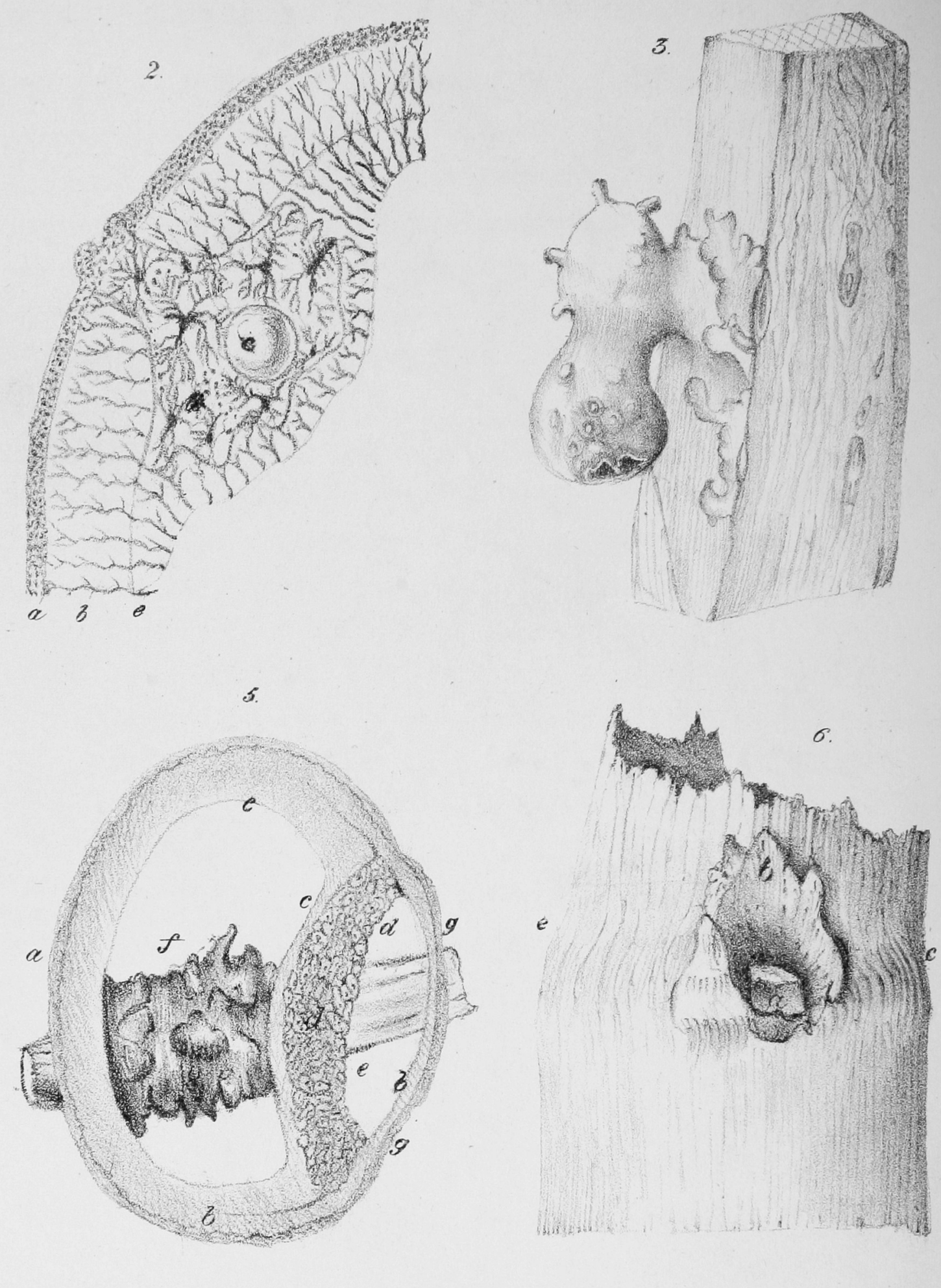

8
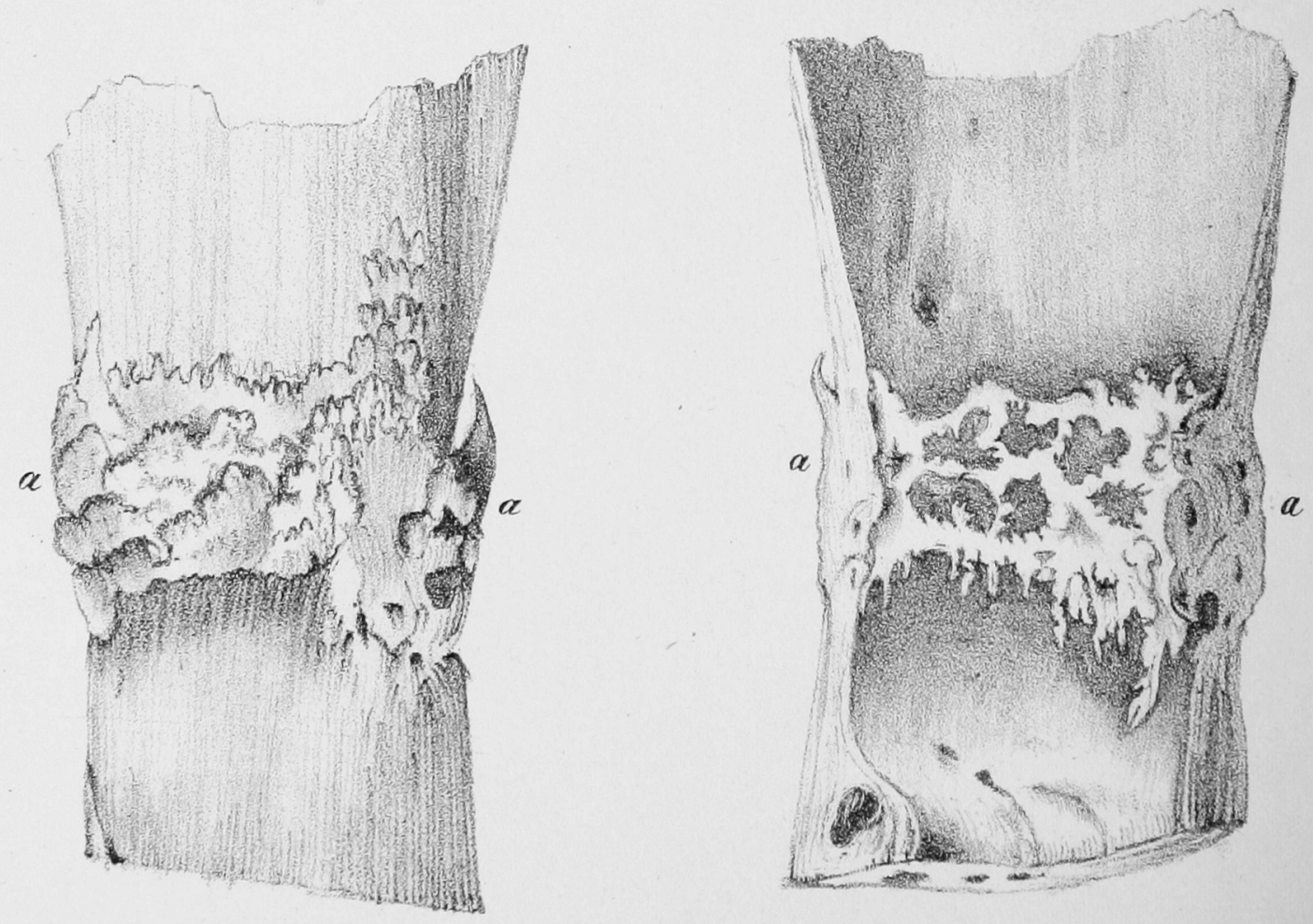
or that it can throw out ossific juice to produce cicatrices; and leads us to believe that CuviER, in denying the possibility of the obliteration of a shot-hole, had allowed himself to be deceived. All difficulties are got over, and contradictions reconciled, by bearing in mind the different circumstances insisted upon in this paper, namely,

1. That a tusk is an endogenous as well as an exogenous organ.

2. That the pulp forms irregular ivory round foreign bodies, and at wounds on its surface.

3. That the membrane of the follicle is an important agent in closing up the holes produced by foreign bodies which penetrate a tusk through the socket.

\section{EXPLANATION OF PLATE I.}

Fig. 1. A portion of a section of a wounded tusk; $a$ cement; $b$ regular ivory deposited previous to the wound ; $c$ irregular ivory deposited after the wound.

Fig. 2. A diagram illustrative of the mode of connection between the Retzian tubes of the primary and secondary regular ivory, and the cells and Retzian tubes of the different mosculating systems of the irregular ivory, after inclosure of a ball ; $a$ cement with its osseous corpuscles; $b$ primary regular ivory with its Retzian tubes ; $c$ the ball ; $d$ the irregular ivory with its systems of tubes and cells ; $e$ secondary regular ivory.

Fig. 3. A copper ball inclosed in a sphere of irregular ivory, on the surface of which are the orifices of Haversian canals. Some of the orifices have closed, and present the appearance of irregular projections. The mass has begun to be attached to the regular ivory of the tusk, and would in time have been inclosed in it. The ball must either have passed across from the opposite side of the tusk, or must have sunk below the level of the hole by which it entered.

Fig. 4. Section of a tusk across the cavity of which a ball has passed, and become inclosed in the ivory of the wall opposite the hole by which it entered. The hole is filled with irregular ivory, coated externally with cement. The cement over the ball has been disarranged by the shock. This section proves that the track of a ball across the pulp is not necessarily ossified.

Fig. 5. Section of a tusk across the base of which a spear-head has penetrated and remained in the wound. The weapon has therefore been separated from the pulp by deposition of irregular ivory in the form of a tube; $a$ cement; $b b$ irregular ivory deposited previous to the wound; $c c$ regular ivory deposited after the wound; $d$ irregular ivory inclosing a vacant space $e$, the seat of an abscess or sinus, and continuous with the cavity of $f$, a mass of irregular ivory (coated with regular ivory) in the form of a tube surrounding the foreign body. As irregular ivory always contracts in drying, more than any other kind of dental substance, that portion of the section marked $g g$ has been bent outwards.

Fig. 6. The same section viewed in profile; $a$ the broken shaft of the spear; $b$ an irregular mass of cement formed round the orifice of the wound by the membrane of the tusk follicle, and which would have closed the wound had the weapon been removed. The wound inflicted has in this instance, as in many others, stunted the growth of the tusk at $c c$, so as to render the part formed after the injury harrower and weaker.

Fig. 7. A longitudinal section of a tusk in which a gun-shot wound had terminated in abscess of the pulp ; $a$ a cement; $b b$ regular ivory deposited before the injury; $c c$ regular ivory deposited after the in- 
100 MR GOODSIR ON MUSKET-BULLETS FOUND IN THE TUSKS OF THE ELEPHANT.

jury; $d d$ irregular ivory bounding the abscess; $e e$ masses of cement and irregular ivory at the margin of the shot-hole.

Fig. 8. The external aspect of a portion of a tusk, which had been transversely fractured; $a$ a the line of fracture united externally by irregular masses of cement.

Fig. 9. The internal aspect of the same portion of tusk; $a a$ the line of fracture united by irregular ivory, a portion of which is arranged in a reticular form. This reticular ivory is interesting, as affording a natural analysis of the peculiar arrangement of parts in the irregular ivory described in the paper. Each bar of the reticular ivory is traversed longitudinally by a medullary canal, from which radiate secondary canals and Retzian tubes, the whole being coated with regular ivory. This reticular ivory differs from the ordinary form of ossified pulp, only in the greater distance between the Haversian or medullary canals, so that portions of the pulp have remained unossified between them. 